\title{
Inter-individual variation in provisioning rate, prey size and number, and links to total prey biomass delivered to nestlings in the Collared Flycatcher (Ficedula albicollis)
}

\author{
Laure Cauchard $^{1^{*}}\left(\mathbb{0}\right.$, Elise Isabella Macqueen ${ }^{1}$, Rhona Lilley ${ }^{1}$, Pierre Bize ${ }^{1 \dagger}$ and Blandine Doligez ${ }^{2,3 \dagger}$
}

\begin{abstract}
Background: In bird species where offspring growth and survival rely on parents' food provisioning, parents can maximise their fitness by increasing the quantity and/or the quality of preys delivered to their offspring. Many studies have focused on inter-individual variation in feeding rate, yet this measure may not accurately reflect the total amount of food (i.e. energy) provided by parents if there is large variation in the quantity and quality of preys at each feeding. Here, we explored the relative role of individual (sex, age, body condition), breeding (hatching date, brood size) and environmental (temperature) factors on feeding rate, prey number, size and quality, and their contribution to total prey biomass delivered to the nestlings of 164 Collared Flycatcher (Ficedula albicollis) parents in 98 nests.

Results: Preys delivered to the nest were mainly larvae (53.6\%) and flying insects (45.6\%). Feeding rate increased with brood size and age, and was higher in males than females. Mean prey number decreased, but mean prey size increased, as the season progressed and parents feeding their brood with primary larvae brought more preys per visit. Relationships between feeding rate, mean prey number and size remained when taking into account the provisioning quality: parents brought either a large number of small prey or a small number of larger items, and the force of the trade-offs between feeding rate and mean prey number and size depended on the quality of the provisioning of the parents. Whatever the percentage of larvae among preys in the provisioning, the variance in total prey biomass was foremost explained by feeding rate (65.1\% to $76.6 \%)$ compared to mean prey number (16.4\% to $26 \%$ ) and prey size (2.7\% to $4 \%)$.
\end{abstract}

Conclusions: Our study shows that variation in feeding rate, prey number, size, but not quality (i.e. percentage of larvae), were influenced by individual factors (sex and age) and breeding decisions (brood size and timing of breeding) and that, whatever the provisioning strategy adopted, feeding rate was the best proxy of the total biomass delivered to the nestlings.

Keywords: Collared Flycatcher, Feeding rate, Foraging, Niche breadth, Prey selection, Provisioning strategy, Reproductive investment

*Correspondence: laure.cauchard@abdn.ac.uk

†Pierre Bize and Blandine Doligez share senior authorship

${ }^{1}$ School of Biological Sciences, University of Aberdeen, Aberdeen, UK

Full list of author information is available at the end of the article

\section{Background}

In birds, provisioning behaviour is strongly associated with reproductive success due to the high-energy demands by young during the period of fast growth (Daunt et al. 2007; Austin et al. 2020). To maximise the energy delivered to their young, parents can use different

c) The Author(s) 2021. This article is licensed under a Creative Commons Attribution 4.0 International License, which permits use, sharing, adaptation, distribution and reproduction in any medium or format, as long as you give appropriate credit to the original author(s) and the source, provide a link to the Creative Commons licence, and indicate if changes were made. The images or other third party material in this article are included in the article's Creative Commons licence, unless indicated otherwise in a credit line to the material. If material is not included in the article's Creative Commons licence and your intended use is not permitted by statutory regulation or exceeds the permitted use, you will need to obtain permission directly from the copyright holder. To view a copy of this licence, visit http://creativeco mmons.org/licenses/by/4.0/. The Creative Commons Public Domain Dedication waiver (http://creativecommons.org/publicdomain/ zero/1.0/) applies to the data made available in this article, unless otherwise stated in a credit line to the data. 
nonexclusive provisioning behaviour strategies: they can (a) deliver preys at a fast rate, $(b)$ bring many prey items per foraging trip, $(c)$ bring large items, and/or $(d)$ deliver preys with high energy and nutrient contents (Ramsay and Houston 2003; Sexton et al. 2017). Most of the studies on provisioning behaviour so far have focused on the factors accounting for variations in feeding rate (i.e. strategy a) (Christe et al. 1996; Møller and Jennions 2001). The sources of variations in prey number, size and quality (strategies $b$ to $d$ ) and their importance in shaping the total amount of energy delivered to the nestlings remain less explored (Wright et al. 1998; Mägi et al. 2009; Bowers et al. 2014; Funghi et al; 2019). For example, higher breeding success could be counterintuitively associated to lower feeding rate when chicks are provisioned with higher quality preys and parents need less visits to reach offspring energy demands (Mägi et al. 2009). In this case, provisioning rate alone would not be a good proxy for breeding success. Hence, studies exploring detailed provisioning strategies beyond measures of feeding rate are needed in order to identify the main sources of variation in provisioning behaviour and test the relative contribution of the different provisioning behavioural parameters to the total biomass delivered to the nest. Furthermore, as provisioning strategies and energy fluxes can be influenced by the trade-off between prey quality and quantity (Magrath et al. 2004; Mägi et al. 2009; Espíndola-Hernández et al. 2017), studies investigating the influence of prey quality on quantitative metrics of provisioning rate (such as feeding rate, prey number and size) may help to gain new insights on individual variation in provisioning strategies.

Inter-individual variation in provisioning has frequently been reported in birds. The sources of variation can be broadly divided in at least three categories. First, variation in provisioning can be related to individual factors such as sex, body condition, age and experience. For example, males are often found to feed their young at lower rates than females, which can be driven by their uncertainty in paternity (Sheldon and Ellegren 1998; Gao et al. 2020). Parental effort may also be traded against body condition maintenance due to the trade-off in the allocation of limited energy between current and future reproduction (Verhulst and Nilsson 2008). Individuals may also increase reproductive effort when reaching old ages, to maximise their last reproductive output (Pärt et al. 1992; Froy et al. 2013), or when inexperienced, to reach the chicks' energy demands (Cichoñ 2003). Interindividual differences in cognitive abilities might also shape variation in provisioning behaviour because skills such as searching for, catching and handling preys might have to be learned so that wiser birds may demonstrate a higher foraging efficiency (Rutz et al. 2006; Cauchard et al. 2017; McLeay et al. 2017; Franks and Thorogood 2018). Second, variation in provisioning behaviour can also arise from breeding decisions such as the timing of breeding and the number of chicks to feed. Indeed, individuals starting breeding earlier might secure higher quality breeding sites/territories (Kokko 1999), although breeding in synchrony (i.e. not too early or too late) with the peak of food resources determines the access to food resources (Both et al. 2006; Verhulst and Nilsson 2008). Furthermore, parents of large broods could maximise the energy delivered to the brood by concentrating on caterpillars (Moreno et al. 1995) rather than nutritious (as they contain more of the amino acid taurine important of nestling development; Ramsay and Houston 2003) but low energy contents spiders (Wiebe and Slagsvold 2015; Espíndola-Hernández et al. 2017). Finally, environmental factors such as temperature or rainfall are likely to influence provisioning by affecting both parent's ability to forage (Sanz and Tinbergen 1999; McKechnie and Wolf 2010; Wiley and Ridley 2016) and prey availability (Funghi et al. 2019; Vincens and Bosch 2000).

In this study, we explored the relative role of individual factors (sex, age, body condition), breeding decisions (timing of the season, brood size) and environmental factors (temperature) on feeding rate, number, size and type of preys delivered to the nestlings in a wild population of Collared Flycatchers (Ficedula albicollis). Collared Flycatchers typically prey on flying insects on the wing, but during the rearing period, they also forage on the foliage and on the ground for caterpillars and other crawling insects (Gustafsson 1989), which both have a higher energy content than flying insects and require less energy to capture (Barba et al. 1996). Because provisioning parameters such as feeding rate, number and size of preys can differ across individuals based on the quality of their provisioning (e.g. percentage of larvae among preys, Espíndola-Hernández et al. 2017), we first investigated the individual, breeding and environmental factors influencing the percentage of larvae among preys. Then, we controlled for this percentage of larvae when analysing individual variation in feeding rate, number and size of preys depending on the same individual, breeding and environmental, factors. This approach allowed us to examine to what extent feeding rate alone, which is widely used in the literature as a non-invasive proxy of food intake, provides a reliable measure of the quality and quantity of the prey biomass delivered to the nestlings.

\section{Methods}

\section{Study site and population monitoring}

The study was conducted on 164 (95 females and 69 males, corresponding to 98 nests) Collared Flycatchers, breeding on the island of Gotland, Sweden $\left(57^{\circ} 07^{\prime} \mathrm{N}, 18^{\circ}\right.$ 
$20^{\prime}$ E) between April and July 2015. This patchy population of small, migratory hole-nesting passerine birds has been monitored each year since 1980 . Flycatchers readily accept to breed in artificial nest boxes, providing an easy access to recording breeding data and behaviour at the nest (Doligez et al. 2004). Collared Flycatchers display biparental care and feed on average 3 to 5 young from late May to early July during 16 days until fledging.

Nests were visited at least every four days to collect data on laying and hatching dates, clutch and brood size (at day 8, 2-3 days after provisioning videos), and final breeding success. When chicks were 8 to 14 days old, adults were caught and identified using individually numbered rings. They were sexed (based on plumage sexual dimorphism (i.e. males are black and white while females are brownish) and aged (yearling vs. 2 years old or older, based on plumage characteristics, Svensson 1992), and measured (tarsus length, to the nearest $0.1 \mathrm{~mm}$, and body mass, to the nearest $0.1 \mathrm{~g}$ ). Body condition was computed as the body mass divided by tarsus length (Doligez et al. 2004).

Data on daily temperature were obtained from the weather centre 02679 in Hoburgen, Gotland $\left(56^{\circ} 55^{\prime} \mathrm{N}\right.$, $18^{\circ} 09^{\prime} \mathrm{E} ; 36 \mathrm{~m}$ ), which is located around $20 \mathrm{~km}$ from our field site. We used the mean daily temperature in Celsius degrees.

\section{Food provisioning}

Food provisioning behaviour was recorded during $1 \mathrm{~h} 20$ between 06:00 and 13:00 (previous study in the same population showed no variation in the provisioning rate using the same temporal window; Sheldon et al. 1997) when nestlings were 5-6 days old, i.e. during the peak of daily parental activity and nestling growth (Krist et al. 2004; Rosivall et al. 2009). An IR camera was installed in the nest box on the day before the recording to let birds habituate to the device. Videos to be analysed were randomly attributed between two observers (EIM and RL) blind to the individual and environmental variables subsequently used in statistical models. Using the motion-detection software programme Motion Meerkat (Weinstein 2015), we recorded for each parental visit the following parameters: (1) entrance and exit time, (2) number of preys delivered, (3) prey categories divided into 4 groups: caterpillar, flying insect, spider or undetermined, (4) prey size on a scale of $1-4$, with 1 for preys smaller than beak length, 2 for preys of about beak length, 3 for preys twice longer than beak length and 4 for preys three times longer than beak length or bigger.

For each individual, we extracted five descriptors of provisioning behaviour: (a) mean number of prey per visit, (b) mean prey size per visit, (c) feeding rate per hour, computed as the total number of feeding visits that occurred from the time the bird first appeared on the video until the end of the video divided by the time interval in hours, (d) total prey biomass delivered to the nestlings per hour, computed as mean number of prey per visit $\times$ mean size of prey per visit $\times$ feeding rate per hour, and e) the percentage of larvae over the total number of preys delivered to the nestlings per hour.

Preliminary analyses of 147 visits by the two observers showed that they differ in how they scored prey number and size per visit: one observer counted more preys (paired $t$-test: $t_{146}=-4.00, P<0.001$; mean $[95 \% \mathrm{CI}]$ difference $=0.35[0.18 ; 0.53]$ ) but sized preys as smaller $\left(t_{146}=8.69, P<0.001 ;-0.50[-0.61 ;-0.38]\right)$ than the other observer. There were no differences in the prey category. Hence, we standardized mean prey size and mean prey number using mean differences between observers as correction factors for subsequent statistical analyses.

\section{Statistical analyses}

The quality of the food delivered to the nestlings by a parent can influence his strategy (i.e. provisioning frequency and number/size/type of items per visit). We thus first examined the variation of the proportion of larvae delivered to the nestlings and controlled for it when further investigating the individual and environmental factors on provisioning parameters.

We investigated the influence of individual and environmental factors on provisioning behaviour by running three sets of generalised linear mixed effect models with (1) mean prey number per visit, (2) mean prey size per visit and (3) feeding rate. We included as random effects the forest patch to account for potential spatial variation in prey availability and nest box to account for the non-independence of both parents in a pair. We included sex, age, body condition, hatching date, brood size at day 8 , mean daily temperature and the percentage of larvae as fixed variables, plus all possible two-way interactions between sex or age and the other fixed effects. Interactions were removed from the models if non-significant.

We then characterized food provisioning strategies by assessing partial correlations between mean prey number and size per visit and provisioning rate. To outline differences when looking for provisioning quantity or quality, we divided parents into three categories depending on whether they were bringing few larvae in the preys, a mix of larvae and other insects, or mostly larvae. We used tertiles in the percentage of larvae in the preys to build up our three categories.

Finally, we assessed the relative contributions of mean prey number and size per visit and feeding rate to the total prey biomass delivered to the nestlings per hour using used multiple linear regression models. We split the analyses in parents provisioning their nest with larvae 
in the preys, a mix of larvae and other insects, or mostly larvae, to investigate whether the type of preys brought influenced the relationships between provisioning variables and total prey biomass delivered to the nestlings.

Data analyses were carried out in the version 3.5.0 of the statistical freeware R cran (R Core Team 2016). Continuous explanatory variables were scaled before analysis to improve the interpretability of our model estimates (Schielzeth 2010). Mean estimates and 95\% confidence intervals are reported in the results; intervals that do not overlap with 0 are considered as significant.

\section{Results}

Provisioning behaviour was recorded during $80 \mathrm{~min}$ on 98 nests, corresponding to 164 parents actively provisioning their chicks ( 95 females and 69 males). The main prey items delivered to the nestlings were larvae (53.6\%; 2033 out of 3795 preys) followed by flying insects (45.6\%; 1731 preys). Spiders and preys that could not be classified represented less than $1 \%$ of the preys ( 23 spiders and 8 non-classified).

\section{Factors influencing the proportion of larvae delivered to the nestlings}

Although the proportion of larvae delivered to the nestlings greatly varied across individuals (Fig. 1), none of the individual, breeding and environmental factors considered in this study significantly explained variation in this trait (all $P$-values $>0.1$; Table 1 ).

\section{Factors influencing provisioning variables}

Feeding rate per hour increased significantly with brood size (mean scaled estimate $[95 \% \mathrm{CI}]=2.50[1.67 ; 3.33]$; Fig. 2a), was higher in males compared to females (2.05 [ -3.96 ; -0.15$]$; Fig. $2 b)$ and in 2 years old or older

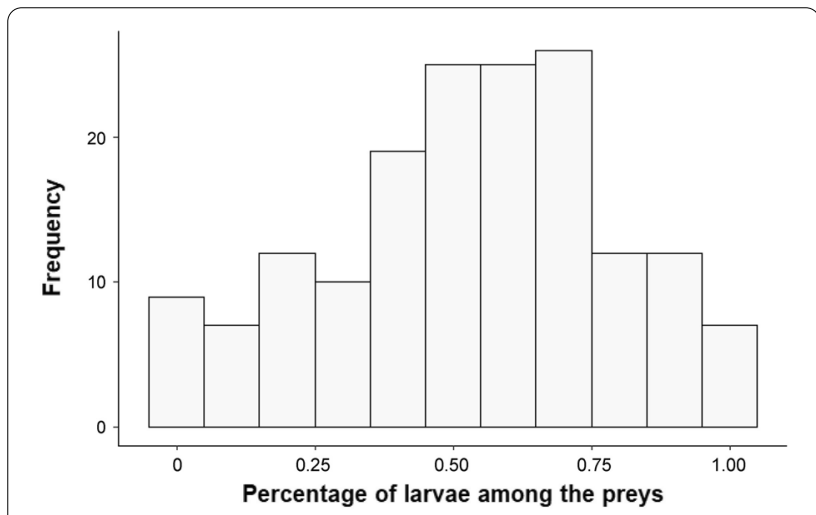

Fig. 1 Distribution of the percentage of larvae among the preys delivered to the nestlings in 80 min by parent Collared Flycatchers. Data are on 164 parents (95 females and 69 males)
Table 1 Results of mixed models testing the effects of individual, breeding and environmental factors on provisioning parameters

\begin{tabular}{lcrrr}
\hline Effect & DFNum & DFDen & \multicolumn{2}{l}{$P$} \\
\hline Percentage of larvae among the preys & & & \\
Vresidual $=0.046(N=152)$. Vnestbox $=0.002$ & $(N=91)$. & & \\
Varea $=0.025(N=13)$ & & 88.1 & -0.40 & 0.687 \\
Sex $[\mathrm{M}]$ & 1 & 134.3 & -0.75 & 0.452 \\
Age $[\mathrm{Y}]$ & 1 & 138.5 & 0.47 & 0.639 \\
Body condition & 1 & 85.6 & -0.71 & 0.479 \\
Hatching date & 1 & 89.9 & -0.05 & 0.957 \\
Brood size & 1 & 76.4 & 0.73 & 0.466 \\
Ambient temperature & 1 & & &
\end{tabular}

\section{Feeding rate}

Vresidual $=22.338(N=152)$. Vnestbox $=0.000(N=91)$. Varea $=3.688(N=13)$

$\begin{array}{llrrr}\text { Sex }[M] & 1 & 137.2 & 2.24 & 0.027 \\ \text { Age }[Y] & 1 & 138.0 & -2.11 & 0.036 \\ \text { Body condition } & 1 & 142.1 & 0.39 & 0.693 \\ \text { Hatching date } & 1 & 140.3 & 0.96 & 0.337 \\ \text { Brood size } & 1 & 141.1 & 5.90 & <0.001 \\ \text { Ambient temperature } & 1 & 140.9 & -0.12 & 0.905 \\ \begin{array}{l}\text { \% Larvae among the } \\ \text { preys }\end{array} & 1 & 132.0 & -1.56 & 0.121 \\ \end{array}$

Mean prey number

Vresidual $=0.188(N=152)$. Vnestbox $=0.068(N=91)$. Varea $=0.039(N=13)$

$\begin{array}{llrrr}\text { Sex }[\mathrm{M}] & 1 & 82.7 & -0.58 & 0.563 \\ \text { Age }[\mathrm{Y}] & 1 & 124.0 & -1.11 & 0.267 \\ \text { Body condition } & 1 & 132.4 & -1.23 & 0.220 \\ \text { Hatching date } & 1 & 88.3 & -2.65 & 0.009 \\ \text { Brood size } & 1 & 90.6 & 0.24 & 0.808 \\ \text { Ambient temperature } & 1 & 80.2 & 1.88 & 0.064 \\ \begin{array}{l}\text { \% Larvae among the } \\ \text { preys }\end{array} & 1 & 127.7 & 2.90 & 0.004\end{array}$

\section{Mean prey size}

Vresidual $=0.112(N=152)$. Vnestbox $=0.002(N=91)$. Varea $=0.011(\mathrm{~N}=13)$

$\begin{array}{llrrr}\text { Sex }[\mathrm{M}] & 1 & 90.4 & 0.63 & 0.529 \\ \text { Age }[\mathrm{Y}] & 1 & 137.3 & 1.92 & 0.056 \\ \text { Body condition } & 1 & 142.7 & 1.38 & 0.168 \\ \text { Hatching date } & 1 & 86.8 & 2.99 & 0.004 \\ \text { Brood size } & 1 & 93.5 & -1.32 & 0.190 \\ \begin{array}{l}\text { Ambient temperature } \\ \begin{array}{l}\text { \% Larvae among the } \\ \text { preys }\end{array}\end{array} & 1 & 84.0 & -1.55 & 0.123 \\ \end{array}$

The effect of sex is expressed as Males versus Females, and the effect of age as Yearling versus Older adults. Two-way interactions between sex and age, on the one hand, and the other fixed effects, on the other hand were not significant and removed from the final models. Significant fixed effects are reported in italics. Analyses were run on 152 individuals ( 85 females and 67 males) with complete information for all the explanatory variables 

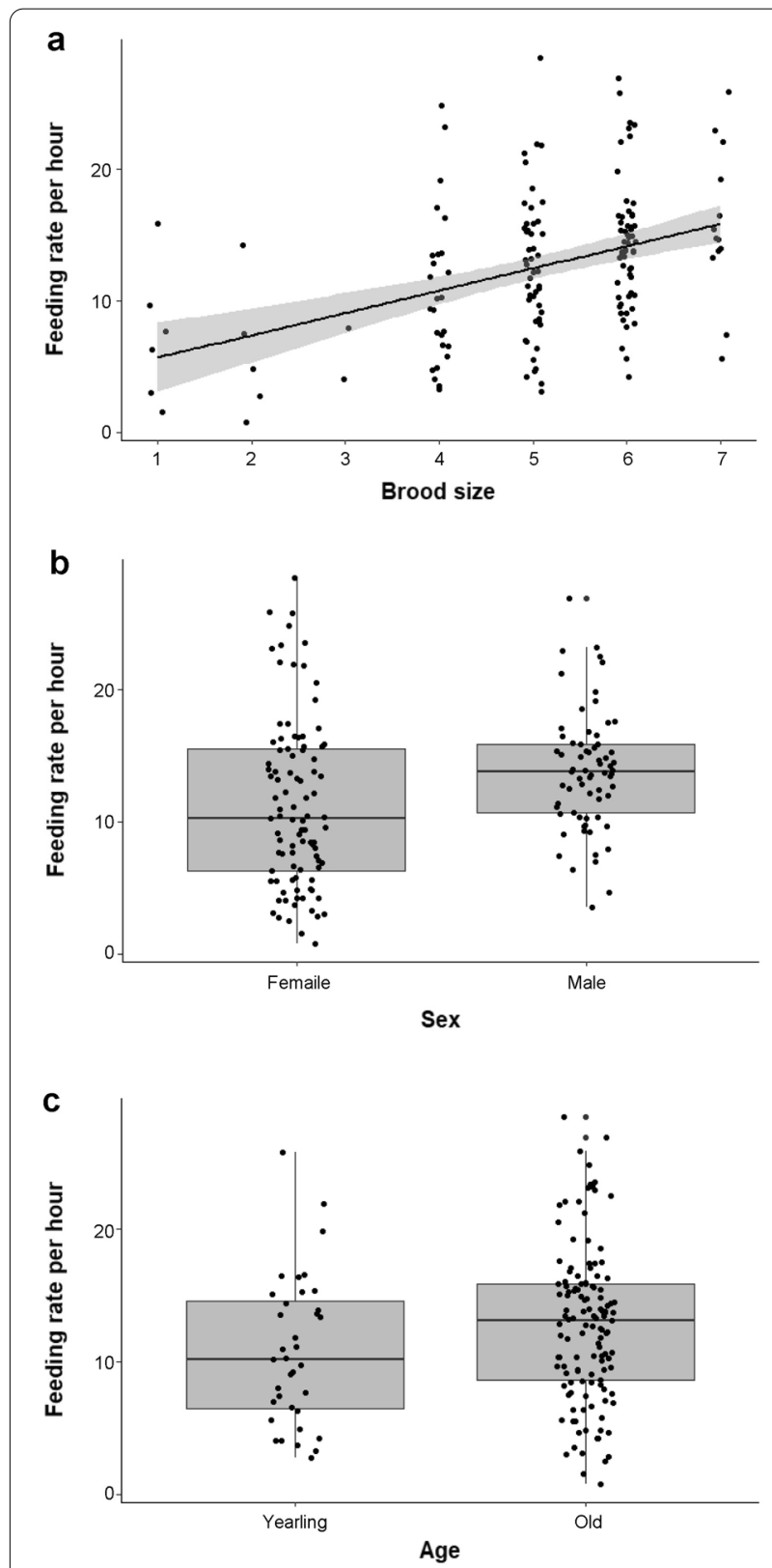

Fig. 2 Feeding rate by parent Collared Flycatchers in relation to (a) brood size, (b) sex, and (c) age category. Data are on 152 individuals (85 females and 67 males)

adults compared to yearlings (2.00 [0.25; 3.76]; Fig. 2c). The feeding rate was neither influenced by the percentage of larvae among the preys $(-0.69[-0.56 ; 0.18])$, nor by adult body condition $(0.19[-0.76 ; 1.15])$, hatching date $(0.41[-0.43 ; 1.25])$ and ambient temperature $(-0.05$ [$0.84 ; 0.75]$ ) (Table 1 ).

The mean number of preys delivered to the nestlings per visit was significantly explained by the percentage of larvae among the preys (mean scaled estimate [95\%

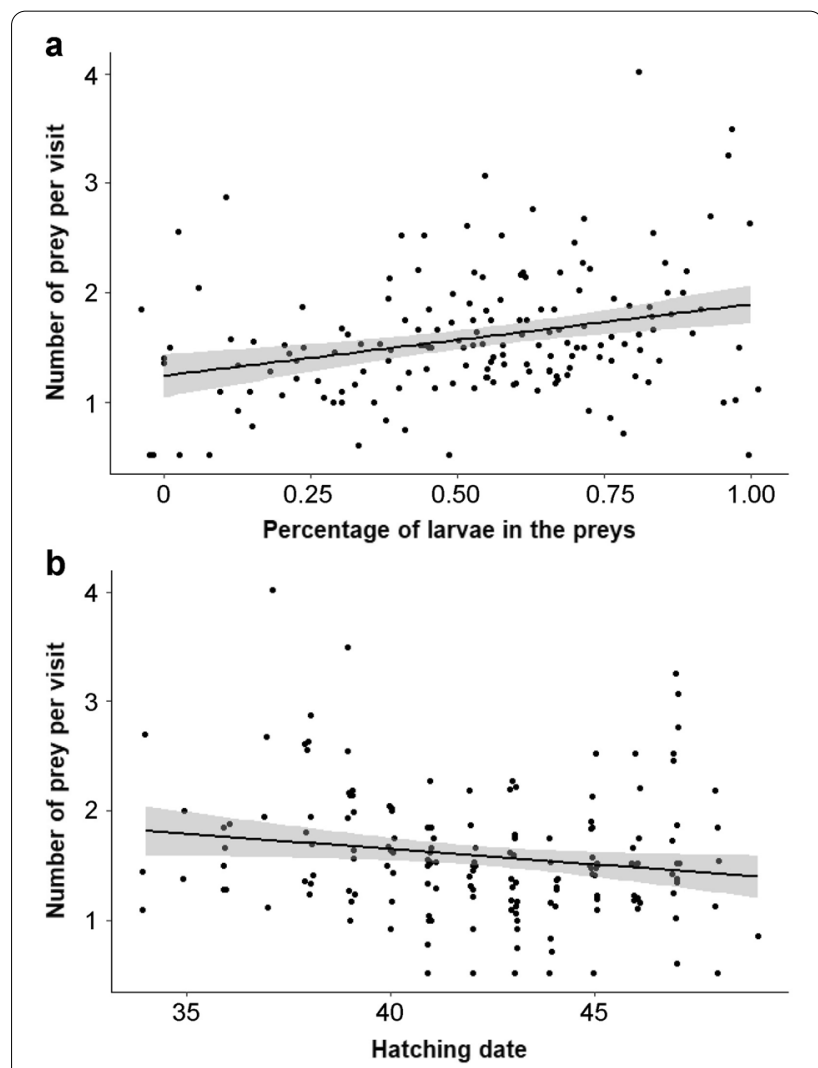

Fig. 3 Number of prey per visit in relation to (a) the percentage of larvae among the preys, (b) hatching date (1 is April 1st). Data are on 152 individuals ( 85 females and 67 males)

$\mathrm{CI}]=0.13[0.04 ; 0.22] ;$ Fig. $3 \mathrm{a})$ and hatching date $(-0.13$ [-0.23; -0.03$]$; Fig. 3b): parents feeding their brood with primary larvae brought more preys per visit and parents delivered less preys as the breeding season progressed. None of the other variables influenced the mean number of preys: sex $(-0.05[-0.02 ; 0.12])$, age $(-0.11$ [-0.30;0.08]), body condition $(-0.06[-0.16 ; 0.04])$, brood size $(0.01[-0.08 ; 0.11])$ or ambient temperature $(0.09[-0.00 ; 0.18])$ (Table 1$)$.

Finally, mean prey size increased with hatching date (mean scaled estimate [95\% CI] $=0.09$ [0.03; 0.15]; Fig. 4): parents brought bigger preys as the breeding season progressed. Mean prey size also tended to increase with age $(0.13$ [ $-0.00 ; 0.27])$ (Table 1$)$. None of the other variables influenced the mean number of preys: sex $(-0.04$ [$0.08 ; 0.16])$, body condition $(0.05[-0.02 ; 0.12])$, brood size $(-0.04[-0.10 ; 0.02])$, ambient temperature $(-0.04$ $[-0.10 ; 0.01])$ or the percentage of larvae $(-0.01[-$ $0.07 ; 0.06])$ (Table 1 ).

\section{Relationships between provisioning variables}

We examined the relationships between mean prey size, number and feeding rate while taking into account for 


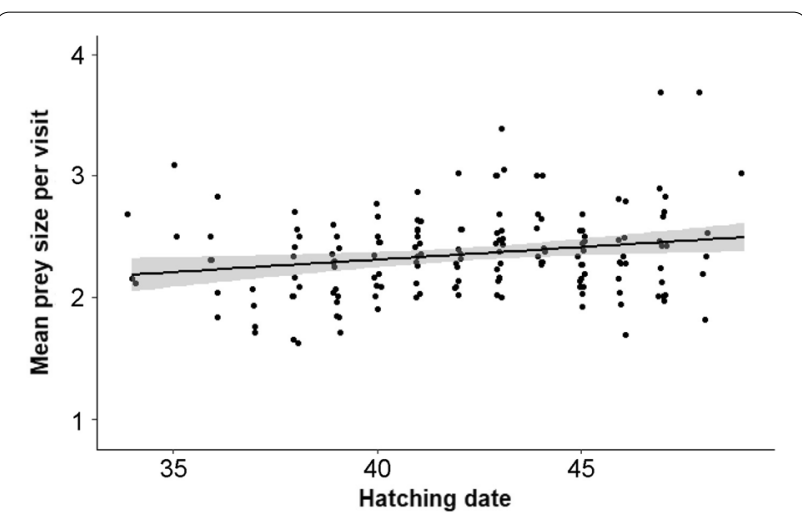

Fig. 4 Mean prey size in relation to hatching date ( 1 is April $1^{\text {st }}$ ). Data are on 152 individuals (85 females and 67 males)

the quality of prey items provisioned by the parents (i.e. percentage of larvae). The first and second tertile in the distribution of the percentage of larvae brough to the nest were at $44.4 \%$ and $66.7 \%$ (Fig. 1). Thus, we compared the relationships between provisioning variables in parents provisioning their chicks with $<44.4 \%$ of larvae in the preys (lower tertile; $n=54$ parents) versus parents provisioning their chicks between 44.4 and $66.7 \%$ of larvae in the preys (middle tertile; $n=53$ parents) versus parents provisioning their chicks with $>66.7 \%$ of larvae in the preys (upper tertile; $n=57$ parents).

Results show a strong trade-off between the mean prey number and mean prey size per visit for a given parent independently of the percentage of larvae in the preys (Table 2). Thus, for each visit, parents provisioned either large numbers of small prey items or small numbers of large items (Fig. 5a). There was evidence for a significant trade-off between feeding rate and mean number of preys brought per visit in parents bringing a mixed of larvae and other insects to their offspring (Table 2), those parents making either fewer visits with many prey items per visit or many visits with few prey items per visit (Fig. 5b). Finally, there was also evidence for a trade-off between feeding rate and mean prey size foremost apparent in parents bringing mostly larvae among the preys (Table 2), those parents making either few visits with large prey items per visit or many visits with small prey items per visit (Fig. 5c).

\section{Provisioning variables explaining the total prey biomass delivered to the nestlings}

Whatever the percentage of larvae delivered to the nestlings by a parent, the variance in total prey biomass per hour delivered to the nestlings was mainly explained by variation in feeding rate $(65.1 \%$ to $67.6 \%$; Table 3$)$ : parents provisioning their chicks with few larvae, a mixed percentage of larvae, or many larvae, increased their total prey biomass delivered to the nestlings while increasing their feeding rate (respectively: mean scaled estimate $[95 \% \mathrm{CI}]=0.88[0.79 ; 0.97], 1.03[0.97 ; 1.08]$, $0.85[0.78 ; 0.92])$. The variance in total prey biomass was also significantly explained by mean prey number and size delivered to the nestlings (Table 3), but to a lower extent, with prey number explaining $16.4 \%$ to $26 \%$ of the variance and prey size explaining $2.7 \%$ to $4.0 \%$ of the variance. Parents provisioning their chicks with few larvae, a mixed percentage of larvae, or many larvae, increased their total prey biomass delivered to the nestlings while increasing the number preys brought per feeding visit (respectively: mean scaled estimate $[95 \% \mathrm{CI}]=0.59$ [0.47; 0.71], 0.60 [0.53;0.67], 0.55 [0.48; 0.62]) and while increasing the size of the preys (respectively: mean scaled estimate $[95 \% \mathrm{CI}]=0.24[0.11 ; 0.36], 0.29[0.22$; $0.36], 0.21[0.14 ; 0.29])$.

Table 2 Results of Pearson's correlations between provisioning parameters depending on the percentage of larvae among the preys delivered to the nestlings in one hour

\begin{tabular}{|c|c|c|c|c|c|c|c|c|c|}
\hline & \multicolumn{9}{|c|}{ Percentage of larvae among the preys } \\
\hline & \multicolumn{3}{|c|}{ 1st tertile (few larvae) } & \multicolumn{3}{|c|}{ 2nd tertile (mixed) } & \multicolumn{3}{|c|}{ 3rd tertile (many larvae) } \\
\hline & \multicolumn{3}{|l|}{$N=54$} & \multicolumn{3}{|l|}{$N=53$} & \multicolumn{3}{|l|}{$N=57$} \\
\hline & $r$ & {$[95 \% \mathrm{Cl}]$} & $P$ & $r$ & {$[95 \% \mathrm{Cl}]$} & $P$ & $r$ & {$[95 \% \mathrm{Cl}]$} & $P$ \\
\hline Prey size_-prey number & -0.692 & {$[-0.810 ;-0.522]$} & $<0.001$ & -0.640 & {$[-0.776 ;-0.447]$} & $<0.001$ & -0.404 & {$[-0.601 ;-0.160]$} & 0.002 \\
\hline Prey number_feeding rate & -0.172 & {$[-0.420 ; 0.100]$} & 0.217 & -0.330 & {$[-0.545 ;-0.057]$} & 0.017 & -0.045 & {$[-0.302 ; 0.218]$} & 0.743 \\
\hline Prey size_-feeding rate & -0.237 & {$[-0.475 ; 0.032]$} & 0.087 & -0.217 & {$[-0.461 ; 0.056]$} & 0.122 & -0.335 & {$[-0.548 ;-0.081]$} & 0.012 \\
\hline
\end{tabular}

Significant fixed effects are reported in bold. Data are divided in 3 tertiles, depending on whether a parent was bringing few larvae $\left(1^{\text {st }}\right.$ tertile; $\left.<44.3 \%\right)$, a mixed of larvae and other preys ( $2^{\text {nd }}$ tertile; $\left.44.3 \%-66.7 \%\right)$, or mostly larvae $\left(3^{\text {rd }}\right.$ tertile; $\left.>66.7 \%\right)$. Data are on 164 individuals 


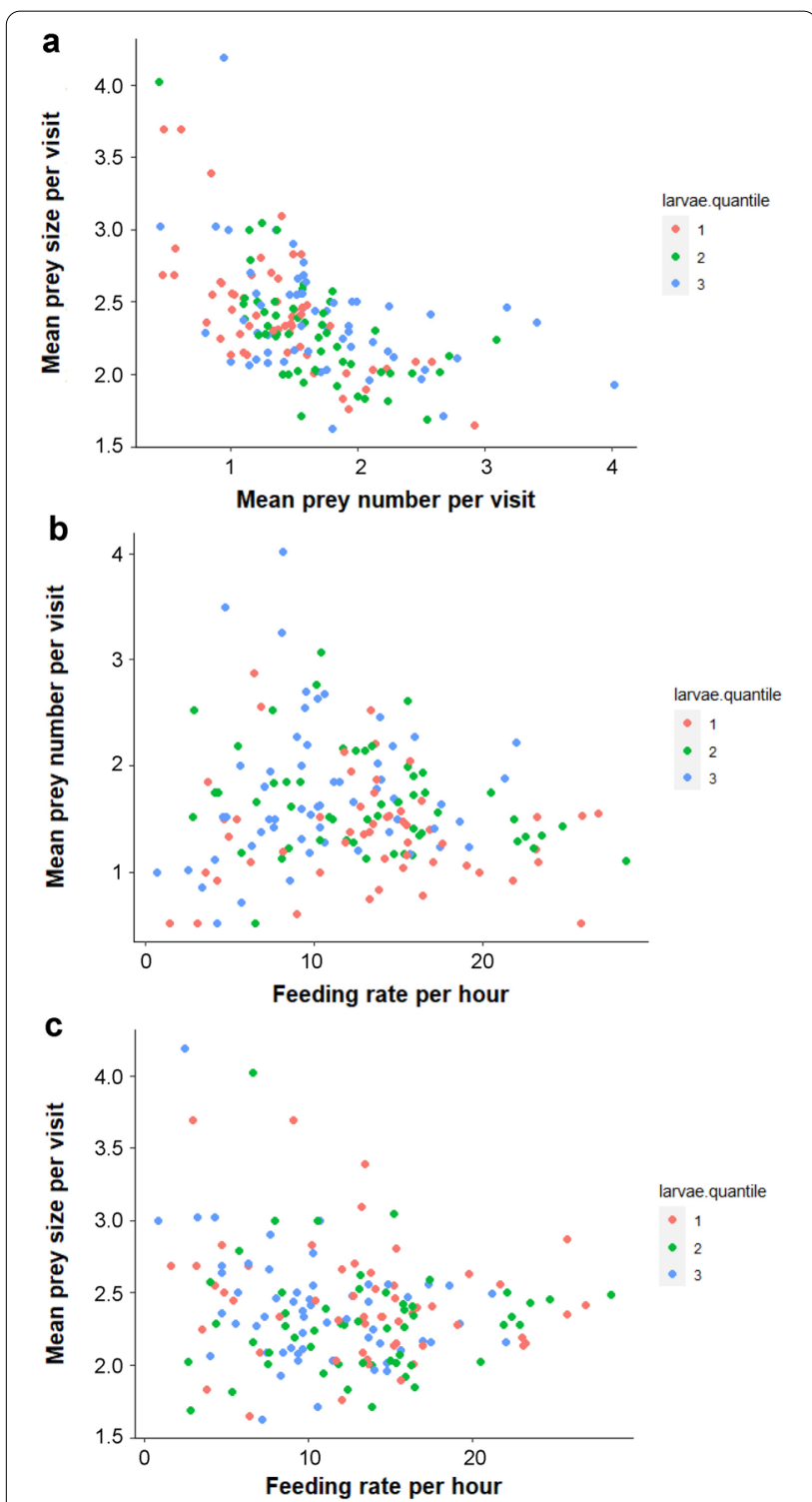

Fig. 5 Mean prey size per visit in relation to (a) mean prey number, and (b) feeding rate per hour; (c) represents mean prey number per visit in relation to feeding rate per hour. Data are on 164 parents (95 females and 69 males)

\section{Discussion}

In this study, we examined to what extent individual, breeding and environmental factors influence parental provisioning strategies, and investigated the relative contribution of feeding rate, prey number and size in influencing the total prey biomass delivered to the nestlings. We found collared flycatcher parents to provision their chicks mainly with larvae (53.6\%) and flying insects (45.6\%).

We found that neither sex, age, body condition, hatching date, brood size or temperature influenced the percentage of larvae among the preys, even if we found a great inter-individual variation in this percentage (Fig. 1). This result could seem surprising, since previous studies found flycatcher's diet to vary with time or sex. Parent Collared Flycatchers were reported to bring mostly caterpillars over other preys when caterpillar abundance is high around the second half of May (Török and Toth 1988). In the closely related Pied Flycatcher (Ficedula hypoleuca), one study reported that females foraged on caterpillars in the tree canopy and males on flying insects caught the wings (Mänd et al. 2013), whereas no differences between sexes in prey types were found in two other studies (Moreno et al. 1995; Siikamäki et al. 1998). Interestingly, the sex difference in foraging niche reported by Mänd et al. (2013) was reduced when environmental conditions became worse (i.e. experimentally increased level of hunger of nestlings). Since the environmental conditions experienced by our population in spring 2015 were relatively unfavourable (i.e. reproductive success in 2015 was lower than in other years, pers. obs.), we cannot exclude that we could have found sex and timing of breeding differences if the study was performed under different conditions. Individuals might also learn specific prey choices throughout their life, so that older birds may select more profitable prey types for nestlings (Forslund and Pärt 1995; Wiebe and Slagsvold 2015). However, again, we did not observe any difference with age in our study although a large sample size on very old birds ( 4 years old and older) would be needed to look at senescence in provisioning parameters in this species.

As previously found in the literature, feeding rate increased mainly with brood size: the more chicks there are the more food parents have to bring back to the nest (Sanz and Tinbergen 1999), including for experimentally enlarged broods (Sendecka et al. 2007). We also found feeding rate to increase with age, in line with previous studies in Collared Flycatchers and other bird species (Pärt et al. 1992; Cichoñ 2003; Froy et al. 2013). This is either because birds may increase reproductive effort when reaching old ages to maximise their last reproductive output (Froy et al. 2013), or because young birds may show a reduced experience in provisioning (Cichoñ 2003) or in securing high quality territories/sites with high quality prey (Slotow and Rothstein 1991; Franks and Thorogood 2018). Feeding rate also varied with sex, but we found males to provision their young more often than females. This result can be surprising, as the reverse is usually found in the literature in species with biparental care (review in Lewis et al. 2002 for seabirds and Kilner 2002 for passerine); however, no difference is often reported too (Moreno et al. 1995; Peck and Congdon 2006). Differences in feeding rate between sexes can arise if males engage in activities such as nest/territory 
Table 3 ANOVA tables reporting the contribution of feeding rate, prey number and size in the total amount of food delivered to the nestlings by parents

\begin{tabular}{|c|c|c|c|c|c|c|c|c|c|c|c|c|c|c|c|}
\hline & \multicolumn{15}{|c|}{ Percentage of larvae among the preys } \\
\hline & \multicolumn{5}{|c|}{ 1st tertile (few larvae) } & \multicolumn{5}{|c|}{ 2nd tertile (mixed) } & \multicolumn{5}{|c|}{ 3rd tertile (many larvae) } \\
\hline & Mean Sq & DF & $F$ & $P$ & & Mean Sq & DF & F & $P$ & & Mean Sq & DF & $F$ & $P$ & \\
\hline Feeding rate & 38.40 & 1 & 362.51 & $<0.001$ & $70.1 \%$ & 48.71 & 1 & 1253.86 & $<0.001$ & $76.6 \%$ & 35.44 & 1 & 628.74 & $<0.001$ & $65.1 \%$ \\
\hline Prey number & 9.55 & 1 & 90.14 & $<0.001$ & $17.4 \%$ & 10.43 & 1 & 268.58 & $<0.001$ & $16.4 \%$ & 14.15 & 1 & 250.93 & $<0.001$ & $26.0 \%$ \\
\hline Prey size & 1.50 & 1 & 14.15 & $<0.001$ & $2.7 \%$ & 2.57 & 1 & 66.15 & $<0.001$ & $4.0 \%$ & 1.89 & 1 & 33.45 & $<0.001$ & $3.5 \%$ \\
\hline Residuals & 5.30 & 50 & & & & 1.90 & 49 & & & & 2.99 & 53 & & & \\
\hline
\end{tabular}

Data are divided in 3 tertiles, depending on whether a parent was bringing few larvae (1st tertile; $<44.3 \%)$, a mixed of larvae and other preys ( 2 nd tertile; $44.3 \%-66.7 \%$ ), or mostly larvae (3rd tertile; $>66.7 \%$ ). Data are on 164 individuals

defence against competitors at the expense of parental care (Qvarnström 1997) or males reduce their parental effort when being uncertain about their paternity in species with extra-pair mating, such as the Collared Flycatcher (Gao et al. 2020). Our result is likely due to the timing of our video recordings: we recorded provisioning early in the morning during the nestling rearing period when females, on top of provisioning, still partly brood nestlings that do not fully thermoregulate yet, while males only provision nestlings (Schwagmeyer et al. 1999). Accordingly, on our videos, males were observed from time to time delivering the prey items that they brought back to the brooding female inside the nest box, and the female then delivered the food to the young. This behaviour both increased the feeding rate of males that were saving time on each visit and decreased the feeding rate of females that were spending more time in the nest box. In our study, the feeding rate was not influenced by the timing of the breeding (i.e. hatching date) nor by the percentage of larvae among the preys. However, our results showed that mean prey size and number per visit varied with the timing of the breeding, as previously found in the literature in various species too (Bowers et al. 2014), and the percentage of larvae among the preys: parents that fed their young mostly with larvae (i.e.> 77\%) brought more preys per visit. Although, we cannot exclude that using only prey length, and thus ignoring their width, height as well as their mass, may have led to a low accurate estimate of prey size.

We then compared the relationship between feeding rate, mean prey size and number per visit, taking into account the percentage of larvae among the preys brought by the parent. Parents with low, medium and high percentage of larvae in their provisioning showed negative correlation between the mean prey number and size per visit, as previously found in the literature (Siikamäki et al. 1998; Wright et al. 1998). However, the feeding rate itself increased when mean prey number decreased, a trade-off that was foremost apparent in parents with a mixed percentage of larvae during provisioning: these parents made either few visits with many prey items per visit or many visits with few prey items per visit. In parents provisioning their brood mainly with larvae or flying insects, the relationships between feeding rate and prey number were negative, but not significantly so. We also found feeding rate to increase when mean prey size decrease, but mainly in parents with a high percentage of larvae during provisioning: these parents made either few visits with large prey items per visit or many visits with small prey items per visit. These results support the hypothesis that quantitative measures of provisioning strategies (i.e. feeding rate, prey number and size) can be influenced by variation in prey quality, as previously reported in the three other insectivorous birds: the Brown Songlark (Cincloramphus cruralis) (Magrath et al. 2004), the Great Tit (Parus major) (Mägi et al. 2009) and the Thorn-tailed Rayadito (Aphrastura spinicauda) (Espíndola-Hernández et al. 2017). In the present study, prey quality had nonetheless only minor consequences on variation in provisioning strategies. This might be partly explained by the crude measure of quality (larvae versus flying) that we used, and ideally information per type of prey on energy content as well as search and handling time should be used to build an index of prey quality (Barba et al. 1996; Mägi et al. 2009; Espíndola-Hernández et al. 2017).

Finally, whatever the percentage of larvae among the preys delivered to the nestlings, the total prey biomass was mainly influenced by the feeding rate: $70.1 \%$, $76.6 \%$ and $65.1 \%$ of the total prey biomass variance was explained by the feeding rate of parents provisioning their chicks with law, mixed or many larvae respectively. Mean prey number explained a lesser part of this variation, explaining $17.4 \%, 16.4 \%$ and $26.0 \%$ respectively. As for mean prey size, it only explained a negligible part of the total biomass, i.e. $2.7 \%, 4.0 \%$ and $3.5 \%$ of the variance. Although nestlings' differences in food 
requirements and in begging behaviour due to sexual differences might influence inter-individual chicks' difference in food intake (Espíndola-Hernández et al. 2017), these results support the use of feeding rate as a good non-invasive proxy of nestlings total food intake during rearing. Our estimate of biomass is based however on estimates of size from pictures, and future studies are needed to validate this crude estimate as an accurate measure of biomass in $\mathrm{g}$ per se.

Besides individual and breeding factors, environmental factors such as meteorological conditions should influence provisioning performance by affecting both parent's ability to forage and prey availability (Funghi et al. 2019). For example, poor environmental conditions, as reflected by low temperature, might affect birds' abilities to locate preferred prey types and/or increase the energetic cost of looking for prey items. Indeed, low temperatures reduce ectothermic preys' metabolism and thus growth and activity for caterpillars, flying insects and spiders (Vincens and Bosch 2000). Moreover, foraging in colder weather is more energy demanding for parents for maintaining both body temperature and activity level (Sanz and Tinbergen 1999), so that birds may not be able to invest as much energy in provisioning compared to warmer days. In the same way, high temperature can cause a stress to breeders that rapidly exceed their physiological tolerance limits (McKechnie and Wolf, 2010) and affect their investment in young (Wiley and Ridley 2016). In our study, environmental factors showed only a small, non-significant, contribution to variation in provisioning traits: only the mean number of preys tended to be affected by temperature, with parents bringing more prey items per visit on warmer days. During our study, daily temperature ranged from $11.6^{\circ} \mathrm{C}$ to $14.8^{\circ} \mathrm{C}$, and it is thus possible that variance was too small in our sample to detect an effect. We were not able to quantify the influence of rainfall because provisioning behaviour was not recorded during heavy rain days, to avoid the risk of further disturbance for the parents known to be in difficult conditions already (our personal observations showed that provisioning was strongly reduced in periods of heavy rain).

\section{Conclusions}

We investigated simultaneously individual, breeding and environmental factors to better understand their effect on Collared Flycatchers provisioning performance. While brood size, sex and age explained variation in feeding rate, only hatching date and the quality of the provisioning explained variation in mean prey number and size per visit. Despite the trade-off in provisioning strategies between prey number and size (i.e. parents make either few visits with many or large prey items per visit, or many visits with few or small prey items per visit), and between feeding rate and mean prey number/size under certain conditions, the total prey biomass brought per hour to the nest was mainly influenced by feeding rate. This result supports the use of feeding rate as an important measure of provisioning in the avian literature.

\section{Acknowledgements \\ We thank the many students that helped with data collection in the field and data extraction back in the laboratory, and all landowners for access to their forest patches}

\section{Authors' contributions}

$\mathrm{LC}$ and $\mathrm{BD}$ designed the study, $\mathrm{LC}$ and BD collected data in the field, EIM, RL and PB analysed videos, and PB performed statistical analyses, LC wrote the first draft of the manuscript and all authors commented. All authors read and approved the final manuscript.

\section{Funding}

This work was supported by grants from the CNRS (PICS) and from the ASAB to BD; the NSERC and FRQNT (postdoctoral fellowship), the ABS and the SCO (student awards), the AMNH, the BOU and the BES (research grants) to LC.

\section{Availability of data and materials}

The datasets generated and/or analysed during the current study are available in the Figshare repository, https://doi.org/10.6084/m9.figshare.14264396.

\section{Declarations}

Ethics approval and consent to participate

Birds were caught, handled and ringed under a licence from the Stockholm Museum Ringing Centre (license number 471:M015 to B.D.) and behavioural tests were conducted in accordance with the Swedish legal requirements applicable in the year of the study.

\section{Consent for publication}

Not applicable

\section{Competing interests}

The authors declare that they have no competing interests.

\section{Author details}

${ }^{1}$ School of Biological Sciences, University of Aberdeen, Aberdeen, UK.

${ }^{2}$ Department of Biometry and Evolutionary Biology, CNRS, University of Lyon, University Lyon 1, Villeurbanne, France. ${ }^{3}$ Animal Ecology, Department of Ecology and Genetics, Evolutionary Biology Centre, Uppsala University, Uppsala, Sweden.

Received: 27 July 2020 Accepted: 15 March 2021

Published online: 09 April 2021

\section{References}

Austin SH, Robinson WD, Robinson TR, Ellis VA, Ricklefs RE. Development syndromes in New World temperate and tropical songbirds. PLoS ONE. 2020;15:e0233627.

Barba E, López JA, Gil-Delgado JA. Prey preparation by adult Great Tits Parus major feeding nestlings. Ibis. 1996;138:532-8.

Both C, Bouwhuis S, Lessells CM, Visser ME. Climate change and population declines in a long-distance migratory bird. Nature. 2006;441:81-3.

Bowers EK, Nietz D, Thompson CF, Sakaluk SK. Parental provisioning in house wrens: effects of varying brood size and consequences for offspring. Behav Ecol. 2014;25:1485-93.

Cauchard L, Angers B, Boogert NJ, Lenarth M, Bize P, Doligez B. An experimental test of a causal link between problem-solving performance and reproductive success in wild Great Tits. Front Ecol Evol. 2017;5:107. 
Christe P, Richner H, Oppliger A. Begging, food provisioning, and nestling competition in great tit broods infested with ectoparasites. Behav Ecol. 1996;7:127-31.

Cichoñ M. Does prior breeding experience improve reproductive success in collared flycatcher females? Oecologia. 2003;134:78-81.

Daunt F, Wanless S, Harris MP, Money L, Monaghan P. Older and wiser: improvements in breeding success are linked to better foraging performance in European shags. Funct Ecol. 2007;21:561-7.

Doligez B, Part T, Danchin E. Prospecting in the collared flycatcher: gathering public information for future breeding habitat selection? Anim Behav. 2004;67:457-66

Espíndola-Hernández P, Castaño-Villa GJ, Vásquez RA, Quirici V. Sex-specific provisioning of nutritious food items in relation to brood sex ratios in a non-dimorphic bird. Behav Ecol Sociobiol. 2017;71:1-8.

Franks VR, Thorogood R. Older and wiser? Age differences in foraging and learning by an endangered passerine. Behav Process. 2018;148:1-9.

Froy H, Phillips RA, Wood AG, Nussey DH, Lewis S. Age-related variation in reproductive traits in the wandering albatross: evidence for terminal improvement following senescence. Ecol Lett. 2013;16:642-9.

Funghi C, McCowan LSC, Schuett W, Griffith SC. High air temperatures induce temporal, spatial and social changes in the foraging behaviour of wild zebra finches. Anim Behav. 2019;149:33-43.

Gao L-F, Zhang H-Y, Zhang W, Sun Y-H, Liang M-J, Du B. Effects of extra-pair paternity and maternity on the provisioning strategies of the Azurewinged Magpie Cyanopica cyanus. Ibis. 2020;162:627-36.

Gustafsson L. Collared flycatcher. Lifetime reproduction in birds. I. Newton. London: Academic Press; 1989. p. 75-88.

Kilner R. Sex differences in canary (Serinus canaria) provisioning rules. Behav Ecol Sociobiol. 2002;52:400-7.

Kokko H. Competition for early arrival in migratory birds. J Anim Ecol. 1999;68:940-50.

Krist M, Remeš V, Uvírová L, Nádvorník P, Bures S. Egg size and offspring performance in the Collared Flycatcher (Ficedula albicollis): a within-clutch approach. Oecologia. 2004;140:52-60.

Lewis S, Benvenuti S, Dall'Antonia L, Griffith R, Money L, Sherrat TN, et al. Sex-specific foraging behaviour in a monomorphic seabird. P Roy Soc B. 2002;269:1687-93.

Mägi M, Mänd R, Tamm H, Sisask E, Kilgas $P$, Tilgar V. Low reproductive success of great tits in the preferred habitat: a role of food availability. Ecoscience. 2009;16:145-57.

Magrath MJ, van Lieshout E, Visser GH, Komdeur J. Nutritional bias as a new mode of adjusting sex allocation. P Roy Soc B. 2004;271:S347-9.

Mänd R, Rasmann E, Mägi M. When a male changes his ways: sex differences in feeding behavior in the pied flycatcher. Behav Ecol. 2013;24:853-8.

McKechnie AE, Wolf BO. Climate change increases the likelihood of catastrophic avian mortality events during extreme heat waves. Biol Lett. 2010;6:253-6.

McLeay LJ, Brad P, Goldsworthy D. But first, are you experienced? The consequences of timing, age, and adult condition on reproductive performance in greater crested terns Thalasseus bergii. Mar Ornithol. 2017:45:205-15

Møller AP, Jennions MD. How important are direct fitness benefits of sexual selection? Naturwissenschaften. 2001:88:401-15.

Moreno J, Cowie RJ, Sanz JJ, Williams RS. Differential response by males and females to brood manipulations in the Pied Flycatcher: Energy expenditure and nestling diet. J Anim Ecol. 1995;64:721-32.

Pärt T, Gustafsson L, Moreno J. Terminal investment and a sexual conflict in the Collared Flycatcher (Ficedula albicollis). Am Soc Nat. 1992;140:868-82.

Peck DR, Congdon BC. Sex-specific chick provisioning and diving behaviour in the wedge-tailed shearwater Puffinus pacificus. J Avian Biol. 2006;37:245-51.
Qvarnström A. Experimentally increased badge size increases male competition and reduces male parental care in the collared flycatcher. P Roy Soc B. 1997:264:1225-31.

R Core Team. R: a language and environment for statistical computing. 2016.

Ramsay SL, Houston DC. Amino acid composition of some woodland arthropods and its implications for breeding tits and other passerines. Ibis. 2003:145:227-32.

Rosivall B, Szöllősi E, Hasselquist D, Török J. Effects of extrapair paternity and sex on nestling growth and condition in the collared flycatcher Ficedula albicollis. Anim Behav. 2009;77:611-7.

Rutz C, Whittingham MJ, Newton M. Age-dependent diet choice in an avian top predator. P Roy Soc B-Biol Sci. 2006;273:579-86.

Sanz JJ, Tinbergen JM. Energy expenditure, nestling age, and brood size: an experimental study of parental behavior in the great tit Parus major. Behav Ecol. 1999;10:598-606.

Schielzeth $\mathrm{H}$. Simple means to improve the interpretability of regression coefficients. Methods Ecol Evol. 2010;1:103-13.

Schwagmeyer PL, Clair RCS, Moodie JD, Lamey TC. Species differences in male parental care in birds: a reexamination of correlates with male paternity. Am Ornithol Soc. 1999:116:487-503.

Sendecka J, Cichoń M, Gustafsson L. Age-dependent reproductive costs and the role of breeding skills in the Collared flycatcher. Acta Zool. 2007;88:95-100.

Sexton JP, Montiel J, Shay JE, Stephens MR, Slatyer RA. Evolution of ecological niche breadth. Annu Rev Ecol Evol Syst. 2017:48:183-206.

Sheldon BC, Ellegren H. Paternal effort related to experimentally manipulated paternity of male Collared Flycatchers. P Roy Soc B-Biol Sci. 1998;265:1737-42.

Sheldon BC, Räsänen K, Dias PC. Certainty of paternity and paternal effort in the collared flycatcher. Behav Ecol. 1997;8:421-8.

Siikamaki P, Haimi J, Hovi M, Ratti O. Properties of food loads delivered to nestlings in the pied flycatcher: Effects of clutch size manipulation, year, and sex. Oecologia. 1998;115:579-85.

Slotow R, Rothstein SI. Importance of dominance status and distance from cover to foraging White-Crowned Sparrows: an experimental analysis. Auk. 1995;112:107-17.

Svensson L. Identification guide to European passerines. Thetford: British Trust for Ornithology; 1992.

Török J, Tòth L. Density dependence in reproduction of the Collared Flycatcher (Ficedula albicollis) at high population levels. J Anim Ecol. 1988;57:251.

Verhulst S, Nilsson J-Å. The timing of birds' breeding seasons: a review of experiments that manipulated timing of breeding. Philos T R Soc B. 2008;363:399-410.

Vicens N, Bosch J. Weather-dependent pollinator activity in an apple orchard, with special reference to Osmia cornuta and Apis mellifera (Hymenoptera: Megachilidae and Apidae). Environ Entomol. 2000;29:413-20.

Weinstein BG. MotionMeerkat: integrating motion video detection and ecological monitoring. Methods Ecol Evol. 2015;6:357-62.

Wiebe KL, Slagsvold T. Foraging trade-offs between prey size, delivery rate and prey type: how does niche breadth and early learning of the foraging niche affect food delivery? Ethology. 2015;121:933-1029.

Wiley EM, Ridley AR. The effects of temperature on offspring provisioning in a cooperative breeder. Anim Behav. 2016;117:187-95.

Wright J, Both C, Cotton PA, Bryant D. Quality vs. quantity: energetic and nutritional trade-offs in parental provisioning. Brit Ecol Soc. 1998;67:620-34. 